Research

Open Access

\title{
Complications of continuous renal replacement therapy in critically ill children: a prospective observational evaluation study
}

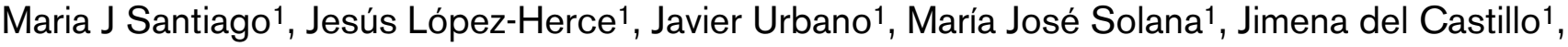 \\ Yolanda Ballestero1, Marta Botrán ${ }^{1}$ and Jose María Bellón²
}

\author{
1Pediatric Intensive Care Service, Hospital General Universitario Gregorio Marañón, Dr Castelo 47 Madrid, 28009, Spain \\ 2Preventive and Quality Control Service, Hospital General Universitario Gregorio Marañón, Dr Castelo 47 Madrid, 28009 Spain \\ Corresponding author: Jesús López-Herce, pielvi@ya.com
}

Received: 3 Sep 2009 Revisions requested: 14 Oct 2009 Revisions received: 27 Oct 2009 Accepted: 23 Nov 2009 Published: 23 Nov 2009

Critical Care 2009, 13:R184 (doi:10.1186/cc8172)

This article is online at: http://ccforum.com/content/13/6/R184

(C) 2009 Santiago et al; licensee BioMed Central Ltd.

This is an open access article distributed under the terms of the Creative Commons Attribution License (http://creativecommons.org/licenses/by/2.0), which permits unrestricted use, distribution, and reproduction in any medium, provided the original work is properly cited.

\begin{abstract}
Introduction Continuous renal replacement therapy (CRRT) frequently gives rise to complications in critically ill children. However, no studies have analyzed these complications prospectively. The purpose of this study was to analyze the complications of CRRT in children and to study the associated risk factors.

Methods A prospective, single-centre, observational study was performed in all critically ill children treated using CRRT in order to determine the incidence of complications related to the technique (problems of catheterization, hypotension at the time of connection to the CRRT, hemorrhage, electrolyte disturbances) and their relationship with patient characteristics, clinical severity, need for vasoactive drugs and mechanical ventilation, and the characteristics of the filtration techniques.
\end{abstract}

Results Of 174 children treated with CRRT, 13 (7.4\%) presented problems of venous catheterization; this complication was significantly more common in children under 12 months of age and in those weighing less than $10 \mathrm{~kg}$. Hypotension on connection to CRRT was detected in 53 patients (30.4\%). Hypotension was not associated with any patient or CRRT characteristics. Clinically significant hemorrhage occurred in 18 patients $(10.3 \%)$; this complication was not related to any of the variables studied. The sodium, chloride, and phosphate levels fell during the first 72 hours of CRRT; the changes in electrolyte levels during the course of treatment were not found to be related to any of the variables analyzed, nor were they associated with mortality.

Conclusions CRRT-related complications are common in children and some are potentially serious. The most common are hypotension at the time of connection and electrolyte disturbances. Strict control and continuous monitoring of the technique are therefore necessary in children on CRRT.

\section{Introduction}

Continuous renal replacement therapy (CRRT) is currently the most widely used technique for extrarenal filtration in critically ill children, because it allows continuous and programmed fluid removal [1-5].

Although a number of studies have demonstrated that these techniques are useful and safe in critically ill children of any age [4-7], complications do occur [8]. Children are at a higher risk than adults for developing complications associated with CRRT due to the difficulty of venous catheterization with the large-caliber catheters required for the technique, the large extracorporeal volume of the system (filters and lines), which predisposes to hypotension at the time of connection, and the need for a more accurate control of volumes in order to avoid fluid and electrolyte disturbances.

There are no studies that have prospectively analyzed the complications or risk factors in children on CRRT.

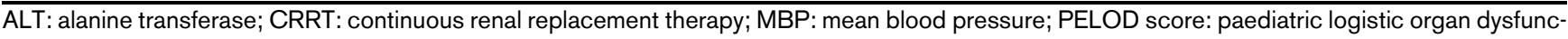
tion score; PIM score: pediatric index of mortality score; PRISM score: pediatric risk of mortality score. 
The objective of the present study was to determine the incidence of complications in children requiring CRRT and to analyze the predisposing risk factors.

\section{Materials and methods}

An analysis was performed of the data from a prospective, single-center register of critically ill children treated using CRRT. The study was approved by the local Institutional Review Board and due to the characteristics of the study inform consent of patients was not considered to be necessary. Between January 1996 and June 2009, CRRT techniques were used in 174 children (105 boys (60.3\%) and 69 girls (39.7\%)) with a mean (standard deviation) age of 52.3 (63.8) months and weight of 17.6 (18.2) kg; $43.7 \%$ of the patients were under one year of age. The most common conditions in patients requiring CRRT were heart disease (55.7\%), particularly during the postoperative period of cardiac surgery, and sepsis (19.5\%).

Two different renal replacement pumps were used to perform CRRT: the BSM321C (Hospal ${ }^{\circledR}$, Barcelona, Spain) in the first 35 patients and the Prisma (Hospal ${ }^{\circledR}$, Barcelona, Spain) in the remaining 139. The caliber of the catheters used was between $4 \mathrm{~F}$ and $11 \mathrm{~F}$ and the filters were between $0.04 \mathrm{~m}^{2}$ and $0.9 \mathrm{~m}^{2}$, according to the age and weight of the patient. All patients received continuous anticoagulation with heparin to maintain an activated coagulation time between 130 and 200 seconds. Other anticoagulant or antiaggregant drugs (citrate, warfarin, aspirin, prostacyclin) were not administered.

The following data were gathered prospectively in all patients on starting CRRT: age; weight; sex; diagnosis; severity scores, pediatric risk of mortality (PRISM II) score [9], pediatric index of mortality (PIM I and II) score [10], pediatric logistic organ dysfunction (PELOD) score only from 2001 [11]; number of organ failures; blood pressure; need for vasoactive drugs; dose of dopamine and adrenaline; lactic acid levels; $\mathrm{pH}$ and base excess; levels of creatinine, urea, alanine transaminase (ALT), bilirubin, sodium, potassium, chloride, calcium, phosphorus, magnesium, albumin and platelets; and type of filtration pump used. The type of connection to CRRT was determined by the physician responsible for the patient. In some cases the connection was made directly to the circuit that had previously been primed using normal saline, in others, after purging with heparin, the system was flushed using $5 \%$ albumin before connection to the patient. During filtration, a daily record was kept of the technique used (hemodiafiltration or hemofiltration), maximum dose of heparin, ultrafiltration rate, life of each filter, electrolyte levels, complications related to the CRRT, and mortality during admission to the pediatric intensive care unit.

The following complications were analyzed: 1) complications of catheterization, defined as hemorrhage with a fall of more than $2 \mathrm{~g} / \mathrm{dL}$ in the hemoglobin concentration and/or hypoten- sion or the need for transfusion and/or withdrawal of the catheter from that site, thrombosis, pneumothorax, and altered limb perfusion; 2) hypotension on connection to the filter, defined as a fall in the mean blood pressure (MBP) of more than 20 $\mathrm{mmHg}$ over baseline and/or an MBP more than two standard deviations below the normal values for age and that required volume expansion and/or an increase in the dose of vasoactive drugs that the patient was receiving in the first 60 minutes after the connection to CRRT; 3) significant hemorrhage, defined as a fall of more than $2 \mathrm{~g} / \mathrm{dL}$ in the hemoglobin concentration in the first 24 hours after bleeding and/or hypotension and that required packed red cell transfusion; and 4) electrolyte disturbances including hyponatremia (sodium $<130 \mathrm{mEq} / \mathrm{L}$ ), hypernatremia (sodium $>150 \mathrm{mEq} / \mathrm{L}$ ), hypokalemia (potassium $<3 \mathrm{mEq} / \mathrm{L}$ ), hyperkalemia (potassium $>5.5$ $\mathrm{mEq} / \mathrm{L}$ ), hypochloremia (chlorine $<95 \mathrm{mEq} / \mathrm{L}$ ), hyperchloremia (chlorine $>115 \mathrm{mEq} / \mathrm{L}$ ), hypocalcemia (total calcium $<8 \mathrm{mg} /$ $\mathrm{dL}$ ), hypercalcemia (total calcium $>12 \mathrm{mg} / \mathrm{dL}$ ), hypophosphatemia (phosphate $<4 \mathrm{mg} / \mathrm{dL}$ in children $<6$ years and phosphate $<3 \mathrm{mg} / \mathrm{dL}$ in children $>6$ years), hyperphosphatemia (phosphate $>7 \mathrm{mg} / \mathrm{dL}$ ), hypomagnesemia (magnesium $<1.5 \mathrm{mg} / \mathrm{dL}$ ), and hypermagnesemia (magnesium $>3$ $\mathrm{mg} / \mathrm{dL}$ ). An analysis was performed of the changes in the electrolyte levels during the first three days of CRRT. The incidence of complications of CRRT between the first seven years and the second seven years of the study was compared.

The statistical analysis of the results was performed using the SPSS statistical package version 14.0. Pearson's chi-squared test and Fisher's exact test were used to compare percentages and the Mann-Whitney test to compare values with a non-parametric distribution. Significance was taken as a $P$ value less than 0.05 .

\section{Results \\ Complications of catheterization}

Complications of catheterization for CRRT occurred in 13 patients $(7.4 \%)$, four of whom presented more than one such complication. The complications included hematoma at the puncture site (6 cases, 3.4\%), hemorrhage (4 cases, $2.2 \%$ ), altered venous drainage of the lower limbs (6 cases, 3.4\%), and incorrect position of the jugular venous catheter requiring change ( 1 case, $0.05 \%$ ). There were no cases of pneumothorax or hemothorax. Patients with complications of catheterization had a significantly lower age and weight than the other patients, and these complications were most common in children younger than 12 months of age and with a weight of less than $10 \mathrm{~kg}$ (Table 1).

There was no relationship between the complications of catheterization and the diagnosis, clinical severity of the patients at the time of starting the technique, need for mechanical ventilation, caliber of the catheter, initial platelet count (Table 1), or venous access used (subclavian, 5\%; jugular, 7.7\%; femoral, $8.2 \% ; P=0.912)$. 
Table 1

Risk factors of catheterization complications in children with CRRT

\begin{tabular}{|c|c|c|c|c|c|}
\hline & \multicolumn{2}{|c|}{ With complications } & \multicolumn{2}{|c|}{ Without complications } & \multirow[t]{2}{*}{$P$} \\
\hline & Mean & SD & Mean & SD & \\
\hline Age (months) & 20.2 & 39.4 & 53.6 & 64.2 & 0.016 \\
\hline Weight (kg) & 8.0 & 10.4 & 17.9 & 18.4 & 0.014 \\
\hline PRISM score & 14.7 & 8.4 & 14.7 & 8.4 & 0.596 \\
\hline PIM score & -2.8 & 1.4 & -1.9 & 1.4 & 0.181 \\
\hline PELOD score & 23.2 & 3.9 & 17.2 & 8.2 & 0.095 \\
\hline Number of failed organs & 2.8 & 1.0 & 2.9 & 1.1 & 0.922 \\
\hline Lactic acid (mmol/L) & 2.1 & 1.2 & 3.1 & 3.7 & 0.725 \\
\hline Arterial pH & 7.27 & 0.1 & 7.32 & 0.1 & 0.416 \\
\hline Mean blood pressure $(\mathrm{mmHg})$ & 53.7 & 27 & 62.0 & 17.9 & 0.173 \\
\hline Dose of adrenaline $(\mu \mathrm{g} / \mathrm{kg} / \mathrm{min})$ & 0.3 & 0.2 & 0.5 & 1.2 & 0.914 \\
\hline Dose of dopamine $(\mu \mathrm{g} / \mathrm{kg} / \mathrm{min})$ & 8.4 & 9.5 & 9.1 & 6.3 & 0.208 \\
\hline Initial creatinine (mg/dL) & 1.3 & 1 & 1.5 & 1.4 & 0.825 \\
\hline Initial urea (mg/dL) & 92.0 & 83.1 & 83.4 & 57.9 & 0.835 \\
\hline ALT (UI/L) & 89.7 & 151.3 & 222.3 & 756.6 & 0.977 \\
\hline Billirubin (mg/dL) & 1.5 & 1.5 & 1.9 & 2.3 & 0.781 \\
\hline \multirow[t]{2}{*}{ Initial platelet count } & 158.583 & 124.291 & 175.425 & 188.538 & 0.821 \\
\hline & \multicolumn{2}{|c|}{ Complications Number $\%$} & \multicolumn{2}{|c|}{ Complications Number $\%$} & \\
\hline \multirow[t]{2}{*}{ Age } & \multicolumn{2}{|c|}{$<12 \mathrm{~m}$} & \multicolumn{2}{|c|}{$>12 \mathrm{~m}$} & \\
\hline & 10 & 13.2 & 3 & 3.1 & 0.013 \\
\hline \multirow[t]{2}{*}{ Sex } & \multicolumn{2}{|c|}{ Male } & \multicolumn{2}{|c|}{ female } & \\
\hline & 8 & 7.8 & 5 & 7.2 & 0.889 \\
\hline \multirow[t]{2}{*}{ Weight } & \multicolumn{2}{|c|}{$<10 \mathrm{~kg}$} & \multicolumn{2}{|c|}{$>10 \mathrm{~kg}$} & \\
\hline & 11 & 12.2 & 2 & 2.4 & 0.015 \\
\hline \multirow[t]{2}{*}{ Diagnoses } & \multicolumn{2}{|c|}{ Cardiopathies } & \multicolumn{2}{|c|}{ Rest of diagnoses } & \\
\hline & 5 & 5.3 & 8 & 10.4 & 0.206 \\
\hline \multirow[t]{2}{*}{ Mechanical ventilation } & \multicolumn{2}{|c|}{ Yes } & \multicolumn{2}{|c|}{ No } & \\
\hline & 11 & 7.6 & 2 & 7.4 & 0.974 \\
\hline \multirow[t]{2}{*}{ Vasoactive drugs } & \multicolumn{2}{|c|}{ Yes } & \multicolumn{2}{|c|}{ No } & \\
\hline & 10 & 7.4 & 3 & 8.3 & 0.843 \\
\hline \multirow[t]{2}{*}{ Initial MAP } & \multicolumn{2}{|c|}{$<55 \mathrm{mmHg}$} & \multicolumn{2}{|c|}{$>55 \mathrm{mmHg}$} & \\
\hline & 8 & 11.4 & 5 & 4.4 & 0.112 \\
\hline
\end{tabular}


Table 1 (Continued)

\begin{tabular}{|c|c|c|c|c|c|}
\hline \multirow[t]{2}{*}{ Initial hypotension } & \multicolumn{2}{|r|}{ Yes } & \multicolumn{3}{|c|}{ No } \\
\hline & 7 & 8.3 & 6 & 6 & 0.530 \\
\hline \multirow[t]{2}{*}{ Dose of adrenaline } & & $>0.6 \mu \mathrm{g} / \mathrm{kg} / \mathrm{min}$ & & $/ \mathrm{kg} / \mathrm{m}$ & \\
\hline & 3 & 8.8 & 7 & 6.4 & 0.632 \\
\hline \multirow[t]{2}{*}{ Catheter size } & & 4 to $6.5 \mathrm{Fr}$ & & $5 \mathrm{Fr}$ & \\
\hline & 10 & 9.8 & 2 & 3.8 & 0.183 \\
\hline \multirow[t]{2}{*}{ Mortality } & & Yes & & o & \\
\hline & 4 & 30.8 & 9 & 36.5 & 0.680 \\
\hline
\end{tabular}

$\mathrm{ALT}=$ alanine transferase $; \mathrm{CRRT}=$ continuous renal replacement therapy; $\mathrm{MAP}=$ mean arterial pressure $\mathrm{PELOD}=$ pediatric logistic organ dysfunction; PIM = pediatric index of mortality; PRIMS = pediatric risk of mortality; SD = standard deviation.

The incidence of complications of catheterization was higher in the first period of the study $14.5 \%$ than in the second period $(4.2 \% ; P=0.01)$.

None of the complications of catheterization gave rise to serious clinical repercussions or prevented the use of CRRT. There was no relation between the complications of catheterization and mortality.

\section{Hypotension at the time of connection to the CRRT}

Before connecting to CRRT, 72 patients (41.3\%) had hypotension. Hypotension was more common in children with heart disease, with greater clinical severity at the time of starting CRRT (evaluated using the PRISM, PIM, and PELOD scores, number of organ failures, lactic acid levels, MBP, need for mechanical ventilation or vasoactive drugs, dose of adrenaline and dopamine before starting CRRT, and liver function (ALT and bilirubin). Children with previous hypotension had a significantly higher mortality than the other children.

On the other hand, hypotension soon after connecting the CRRT occurred in 53 patients (30.4\%). Hypotension on connection to the CRRT was not statistically associated with any patient or CRRT characteristics and there were no differences in the incidence of hypotension between the two periods of the study (Table 2).

It was not possible to determine whether priming with albumin was associated with a need for lower volume expansion or less increase in the dose of vasoactive drugs. We only recorded if hypotension developed and whether or not volume expansion or an increase in the dose of drugs was required, not the actual volume of fluids or dose of drugs administered.

\section{Hemorrhage}

Clinically significant hemorrhage during CRRT occurred in 18 patients (10.3\%). There was no relation between the presence of hemorrhage and age, weight, diagnosis, or clinical severity at the start of CRRT (Table 3). Although the platelet counts were slightly lower in children with hemorrhage, the differences did not reach statistical significance at any time during the course of treatment (Table 3 ). However, patients with bleeding did receive platelet transfusions more frequently. The maximum doses of heparin administered did not differ significantly between patients with hemorrhage and other patients (Table 3). Patients with hemorrhage presented a higher mortality than other patients, although the differences did not reach statistical significance $(P=0.068$; Table 3$)$.

The incidence of clinically significant hemorrhage was slightly higher in the first period of the study $(14.5 \%)$ than in the second period (8.5\%), however, the difference was not significant $(P=0.2)$.

\section{Electrolyte disturbances}

The changes in the electrolyte levels (sodium, potassium, chloride, calcium, phosphorus, and magnesium) over the first 72 hours of CRRT are shown in Figures 1 and 2. In the first 72 hours of CRRT, the levels of sodium, chloride, and phosphate fell significantly, total calcium increased significantly, and the levels of potassium and magnesium remained unaltered. Figures 3 and 4 show the percentage of electrolyte disturbances during the first three days of CRRT. The percentage of patients with raised electrolyte levels decreased progressively during the first three days of therapy (Figure 3). In contrast, the percentage of patients with hyponatremia, hypochloremia, and hypophosphatemia increased significantly during CRRT, requiring an increase in the concentration of these electrolytes in the dialysis and replacement fluids and/or intravenous supplements (Figure 4). The electrolyte disturbances did not lead to clinical manifestations except in one patient in whom Dialisan AFB (Hospal ${ }^{\circledR}$, Barcelona, Spain) was used as the dialysis fluid. This fluid has a sodium concentration of $4725 \mathrm{mEq} / \mathrm{L}$ and requires dilution of $1 \mathrm{~mL}$ in $35 \mathrm{~mL}$ of water before use; in error, the solution was used undiluted for a few hours and the patient presented hypernatremia of $216 \mathrm{mEq} / \mathrm{L}$, hyperchlo- 
Table 2

Risk factors of hypotension during connection of CRRT in children

\begin{tabular}{|c|c|c|c|c|c|}
\hline & \multicolumn{2}{|c|}{ Hypotension } & \multicolumn{2}{|c|}{ No hypotension } & \multirow[t]{2}{*}{$P$} \\
\hline & Mean & SD & Mean & SD & \\
\hline Age (months) & 53.4 & 67.5 & 50.0 & 61.4 & 0.694 \\
\hline Weight $(\mathrm{kg})$ & 18.1 & 19.8 & 16.9 & 17.3 & 0.910 \\
\hline PRISM score & 16.8 & 15.5 & 21.6 & 25.8 & 0.650 \\
\hline PIM score & 10.1 & 13.4 & 10.9 & 16.8 & 0.874 \\
\hline PELOD score & 25.7 & 30.2 & 20.7 & 22.7 & 0.294 \\
\hline Number of failed organs & 3.2 & 1.2 & 2.8 & 1.1 & 0.139 \\
\hline Lactic acid (mmol/L) & 3.2 & 3.3 & 3.0 & 3.8 & 0.357 \\
\hline Arterial pH & 7.32 & 0.12 & 7.31 & 0.10 & 0.341 \\
\hline MAP $(\mathrm{mmHg})$ & 58.2 & 14.8 & 62.9 & 20.2 & 0.124 \\
\hline Dose of adrenaline $(\mu \mathrm{g} / \mathrm{kg} / \mathrm{min})$ & 0.4 & 0.5 & 0.57 & 1.3 & 0.734 \\
\hline Dose of dopamine ( $\mu \mathrm{g} / \mathrm{kg} / \mathrm{min})$ & 9.1 & 6.6 & 9.0 & 6.6 & 0.932 \\
\hline Initial creatinine (mg/dL) & 1.4 & 1.1 & 1.5 & 1.3 & 0.491 \\
\hline Initial urea (mg/dL) & 79.2 & 61.4 & 86.2 & 59.6 & 0.236 \\
\hline ALT (UI/L) & 523.5 & 1261.7 & 71.0 & 112.5 & 0.212 \\
\hline Billirubine (mg/dL) & 1.8 & 1.6 & 1.8 & 2.4 & 0.667 \\
\hline \multirow[t]{2}{*}{ Extracorporeal circuit volume/weight of patient $(\mathrm{ml} / \mathrm{kg})$} & 8.6 & 4.6 & 8.8 & 5.3 & 0.982 \\
\hline & \multicolumn{2}{|c|}{$\begin{array}{c}\text { Hypotension } \\
\text { Number \% }\end{array}$} & \multicolumn{2}{|c|}{$\begin{array}{l}\text { Hypotension } \\
\text { Number \% }\end{array}$} & \\
\hline \multirow[t]{2}{*}{ Age } & \multicolumn{2}{|c|}{$<12 \mathrm{~m}$} & \multicolumn{2}{|c|}{$>12 \mathrm{~m}$} & \\
\hline & 24 & 31.6 & 29 & 30.2 & 0.847 \\
\hline \multirow[t]{2}{*}{ Sex } & \multicolumn{2}{|c|}{ Male } & \multicolumn{2}{|c|}{ Female } & \\
\hline & 34 & 33 & 19 & 27.5 & 0.446 \\
\hline \multirow[t]{2}{*}{ Weight } & \multicolumn{2}{|c|}{$<10 \mathrm{~kg}$} & \multicolumn{2}{|c|}{$>10 \mathrm{~kg}$} & \\
\hline & 27 & 30 & 35 & 31.7 & 0.809 \\
\hline \multirow[t]{2}{*}{ Diagnoses } & \multicolumn{2}{|c|}{ Cardiopathies } & \multicolumn{2}{|c|}{ Rest of diagnoses } & \\
\hline & 31 & 32.6 & 22 & 28.6 & 0.566 \\
\hline \multirow[t]{2}{*}{ Mechanical ventilation } & \multicolumn{2}{|c|}{ Yes } & \multicolumn{2}{|c|}{ No } & \\
\hline & 48 & 33.1 & 5 & 18.5 & 0.132 \\
\hline \multirow[t]{2}{*}{ Vasoactive drugs } & \multicolumn{2}{|c|}{ Yes } & \multicolumn{2}{|c|}{ No } & \\
\hline & 42 & 30.9 & 11 & 30.6 & 0.970 \\
\hline \multirow[t]{2}{*}{ Initial MAP } & \multicolumn{2}{|c|}{$<55 \mathrm{mmHg}$} & \multicolumn{2}{|c|}{$>55 \mathrm{mmHg}$} & \\
\hline & 24 & 38.1 & 25 & 27.5 & 0.164 \\
\hline
\end{tabular}


Table 2 (Continued)

Risk factors of hypotension during connection of CRRT in children

\begin{tabular}{|c|c|c|c|c|c|}
\hline \multirow[t]{2}{*}{ Dose of adrenaline } & \multicolumn{2}{|c|}{$>0.6 \mu \mathrm{g} / \mathrm{kg} / \mathrm{min}$} & \multicolumn{2}{|c|}{$>0.6 \mu \mathrm{g} / \mathrm{kg} / \mathrm{min}$} & \multirow[b]{2}{*}{0.513} \\
\hline & 12 & 35.3 & 32 & 29.4 & \\
\hline \multirow[t]{2}{*}{ Filter surface } & & $3 \mathrm{~m}^{2}$ & & $3 \mathrm{~m}^{2}$ & \\
\hline & 21 & 33.3 & 32 & 24.4 & 0.586 \\
\hline \multirow[t]{2}{*}{ Extracorporeal circuit volume/weight of patient } & & $\mathrm{ml} / \mathbf{k g}$ & & $\mathrm{nl} / \mathbf{k g}$ & \\
\hline & 36 & 32.1 & 10 & 22.2 & 0.217 \\
\hline \multirow[t]{2}{*}{ Mortalilty } & & es & & lo & \\
\hline & 24 & 38.7 & 29 & 26.4 & 0.095 \\
\hline
\end{tabular}

$\mathrm{ALT}=$ alanine transferase; $\mathrm{CRRT}=$ continuous renal replacement therapy; MAP $=$ mean arterial pressure; PELOD $=$ pediatric logistic organ dysfunction; PIM = pediatric index of mortality; PRIMS = pediatric risk of mortality; SD = standard deviation.

remia of $189 \mathrm{mEq} / \mathrm{L}$, and ionic calcium of $4 \mathrm{mmol} / \mathrm{L}$, leading to hypertension and a convulsive crisis. The electrolyte disturbances were corrected by substitution of the dialysis fluid (by a specific CRRT dialysis fluid) [12]; after correction, the patient presented a good clinical course and there have been no neurological or renal sequelae after nine years of follow-up.

The alterations in the electrolyte levels during the course of the study were not related to any of the variables analyzed or to the filtration technique used. There was no correlation between mortality and any of the electrolyte disturbances during the course of the study (data not shown).

\section{Discussion}

Our study is the first that has prospectively investigated complications related to CRRT in critically ill children and that has analyzed the factors associated with these complications.

The percentage of complications of venous catheterization was similar to that found in other studies of central line catheterization in pediatric patients, despite the fact that the catheters necessary for CRRT are larger [13-15]. The complications of catheterization were more common in smaller children because catheterization is more difficult in these patients and because the caliber of the catheter used in infants is proportionally larger than in older children. In contrast to other series, we did not find differences in the rate of complications between the use of veins in the upper body (jugular and subclavian) or lower body (femoral) $[13,15]$. A recent study in adults that compared jugular and femoral venous access for acute CRRT found that the incidence of hematomas was higher in jugular than in femoral access, with no significant differences in the rates of infection secondary to catheterization [16]. The incidence of catheter-related infection was not analyzed in the present study. A recent study has shown that ultrasound-guided central venous catheter placement decreases the complications of catheterization, although we have not used this method in our patients [17].

Hypotension after connection to the CRRT system was the most common complication; it is more common in children because the extracorporeal volume of the circuit and filter used for CRRT represents 10 to $5 \%$ of a patient's blood volume [5]. The circuits used in our study have a priming volume (including the filter) of 50,100 , and $130 \mathrm{~mL}$ depending on the surface area of the filter used $\left(0.04,0.6\right.$, or $0.9 \mathrm{~m}^{2}$, respectively). Although the circuit priming volume is proportionally larger in children of lower weight, we did not find any relation between the frequency of hypotension and age, weight, or surface area of the filters. The design of filters and circuits with a low priming volume is an essential factor in the reduction of hemodynamic complications at the time of connection to the system.

Patients with previous hemodynamic alterations theoretically could have more hypotension after connection to the CRRT. However, surprisingly in our study, we have not found any individual factors associated with hypotension after CRRT connection. It is possible that, although individually each risk factor is not associated with hypotension, the combination of several risk factors such as the extracorporeal volume of the circuit and filter and the previous hemodynamic alterations could influence the development of hypotension after connection to CRRT.

There are a number of techniques that can be used to attempt to reduce the risk of hypotension at the time of connection, such as priming the circuit with whole blood or colloids, although there are no studies that have analyzed their efficacy. Patients on CRRT usually received many blood transfusions. To reduce the risks of transfusion, we decided to more frequently prime the circuit with $5 \%$ albumin rather than with whole blood if the hemoglobin is not very low. However, in our 
Table 3

Risk factors of bleeding complications in children with CRRT

\begin{tabular}{|c|c|c|c|c|c|}
\hline & \multicolumn{2}{|c|}{ Bleeding } & \multicolumn{2}{|c|}{ No bleeding } & \multirow[t]{2}{*}{$P$} \\
\hline & Mean & SD & Mean & SD & \\
\hline Age (months) & 64.2 & 70.8 & 49.5 & 62.3 & 0.385 \\
\hline Weight (kg) & 22.7 & 22.0 & 16.6 & 17.5 & 0.310 \\
\hline PRISM score & 15.0 & 7.0 & 14.7 & 8.5 & 0.643 \\
\hline PIM score & -2.1 & 0.9 & -2.0 & 1.5 & 0.929 \\
\hline PELOD score & 18.1 & 9.2 & 17.5 & 8.1 & 0.402 \\
\hline Number of failed organs & 3.3 & 1.1 & 2.9 & 1.1 & 0.189 \\
\hline Lactic acid (mmol/L) & 4.3 & 5.4 & 2.9 & 3.4 & 0.530 \\
\hline Arterial pH & 7.31 & 0.1 & 7.31 & 0.1 & 0.906 \\
\hline MAP $(\mathrm{mmHg})$ & 56.2 & 22.7 & 62.0 & 18.2 & 0.211 \\
\hline Dose of adrenaline $(\mu \mathrm{g} / \mathrm{kg} / \mathrm{min})$ & 0.5 & 0.6 & 0.5 & 1.2 & 0.409 \\
\hline Dose of dopamine $(\mu \mathrm{g} / \mathrm{kg} / \mathrm{min})$ & 10.9 & 8.2 & 8.8 & 6.3 & 0.295 \\
\hline Initial creatinine (mg/dL) & 1.2 & 0.8 & 1.5 & 1.4 & 0.956 \\
\hline Initial urea (mg/dL) & 93.8 & 68.9 & 82.9 & 59.0 & 0.475 \\
\hline ALT (UI/L) & 174.7 & 171.0 & 209.5 & 776.3 & 0.355 \\
\hline Billirubine (mg/dL) & 3.1 & 4.0 & 1.5 & 1.4 & 0.218 \\
\hline Initial platelet (inicial) & 150.944 & 119.341 & 177.289 & 170.637 & 0.821 \\
\hline Platelet after 24 hours of CRRT & 89.000 & 72.960 & 122.068 & 111.964 & 0.254 \\
\hline Platelet after 48 hours of CRRT & 93.000 & 76.183 & 105.589 & 99.070 & 0.657 \\
\hline Maximum dose of heparin $(\mathrm{Ul} / \mathrm{kg} / \mathrm{h})$ & 14.7 & 13.1 & 15.2 & 10.3 & 0.351 \\
\hline Ultrafiltration rate $(\mathrm{mL} / \mathrm{kg} / \mathrm{h})$ & 43.6 & 34.4 & 37.3 & 25.3 & 0.751 \\
\hline \multirow[t]{2}{*}{ Circuit lifespan (h) } & 47.5 & 61.5 & 41.9 & 36.9 & 0.638 \\
\hline & \multicolumn{2}{|c|}{ Bleeding Number $\%$} & \multicolumn{2}{|c|}{ Bleeding Number $\%$} & \\
\hline \multirow[t]{2}{*}{ Age } & \multicolumn{2}{|c|}{$<12 \mathrm{~m}$} & \multicolumn{2}{|c|}{$>12 \mathrm{~m}$} & \\
\hline & 9 & 11.8 & 9 & 9.4 & 0.600 \\
\hline \multirow[t]{2}{*}{ Sex } & \multicolumn{2}{|c|}{ Male } & \multicolumn{2}{|c|}{ Female } & \\
\hline & 9 & 8.7 & 9 & 13 & 0.366 \\
\hline \multirow[t]{2}{*}{ Weight } & \multicolumn{2}{|c|}{$<10 \mathrm{~kg}$} & \multicolumn{2}{|c|}{$>10 \mathrm{~kg}$} & \\
\hline & 9 & 10 & 9 & 11 & 0.835 \\
\hline \multirow[t]{2}{*}{ Diagnoses } & \multicolumn{2}{|c|}{ Cardiopathies } & \multicolumn{2}{|c|}{ Rest of diagnoses } & \\
\hline & 10 & 10.5 & 8 & 10.4 & 0.977 \\
\hline Mechanical ventilation & & es & & 0 & \\
\hline
\end{tabular}


Table 3 (Continued)

Risk factors of bleeding complications in children with CRRT

\begin{tabular}{|c|c|c|c|c|c|}
\hline & 17 & 11.7 & 1 & 3.7 & 0.211 \\
\hline \multirow[t]{2}{*}{ Vasoactive drugs } & \multicolumn{2}{|r|}{ Yes } & \multicolumn{2}{|c|}{ No } & \\
\hline & 15 & 11 & 3 & 8.3 & 0.638 \\
\hline \multirow[t]{2}{*}{ Initial MAP } & \multicolumn{2}{|r|}{$<55 \mathrm{mmHg}$} & \multicolumn{2}{|c|}{$>55 \mathrm{mmHg}$} & \\
\hline & 11 & 17.5 & 7 & 6.6 & 0.034 \\
\hline \multirow[t]{2}{*}{ Initial hypotension } & \multicolumn{2}{|r|}{ Sí } & \multicolumn{2}{|c|}{ No } & \\
\hline & 10 & 14.3 & 8 & 8.3 & 0.241 \\
\hline \multirow[t]{2}{*}{ Dose of adrenaline } & \multicolumn{2}{|r|}{$>0.6 \mu \mathrm{g} / \mathrm{kg} / \mathrm{min}$} & \multicolumn{2}{|c|}{$>0.6 \mu \mathrm{g} / \mathrm{kg} / \mathrm{min}$} & \\
\hline & 5 & 14.7 & 13 & 11 & 0.561 \\
\hline \multirow[t]{2}{*}{ Platelet } & \multicolumn{2}{|r|}{$<50.000$} & \multicolumn{2}{|c|}{$>50.000$} & \\
\hline & 6 & 20 & 12 & 10.3 & 0.152 \\
\hline \multirow[t]{2}{*}{ Platelet transfusion } & \multicolumn{2}{|r|}{ Sí } & \multicolumn{2}{|c|}{ No } & \\
\hline & 14 & 18.9 & 4 & 4.1 & 0.002 \\
\hline \multirow[t]{2}{*}{ CRRT technique } & \multicolumn{2}{|r|}{ Hemofiltration } & \multicolumn{2}{|c|}{ Hemodiafiltration } & \\
\hline & 3 & 6.7 & 15 & 11.8 & 0.333 \\
\hline \multirow[t]{2}{*}{ Filter surface } & & $<0.3 \mathrm{~m} 2$ & & $\mathrm{~m} 2$ & \\
\hline & 9 & 14.3 & 9 & 14.7 & 0.937 \\
\hline \multirow[t]{2}{*}{ Maximum dose of heparin } & & $>10 \mathrm{U} / \mathrm{kg} / \mathrm{h}$ & & $/ \mathrm{kg} / \mathrm{h}$ & \\
\hline & 7 & 8.4 & 11 & 12.4 & 0.401 \\
\hline \multirow[t]{2}{*}{ Mortality } & & Yes & & & \\
\hline & 10 & $55.6 \%$ & 8 & $33.8 \%$ & 0.068 \\
\hline
\end{tabular}

$\mathrm{ALT}=$ alanine transferase $\mathrm{CRRT}=$ continuous renal replacement therapy; $\mathrm{MAP}=$ mean arterial pressure $\mathrm{PELOD}=$ pediatric logistic organ dysfunction; PIM = pediatric index of mortality; PRIMS = pediatric risk of mortality; SD = standard deviation.

\section{Figure 1}

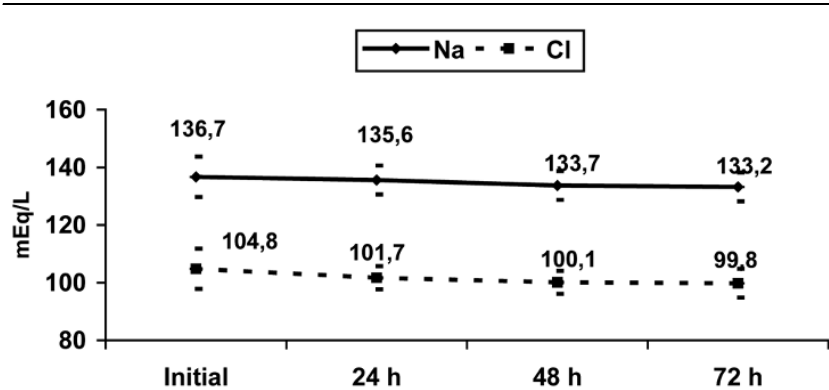

Evolution of sodium and chloride serum levels during the first 72 hours of continuous renal replacement therapy. Mean and standard deviation. study, we did not record in which children the circuit was primed with albumin and we cannot therefore analyze the efficacy of this measure. Further studies are necessary to determine the efficacy of circuit-priming methods in the reduction of hypotension at the time of connection.

The treatment of hypotension was different depending on the situation of each patient. Generally, we used volume expansion with colloids 10 to $20 \mathrm{ml} / \mathrm{kg}$ as the first measure. If the hypotension was severe we also increased the vasoactive drugs that the patient received, and when the haemoglobin level was low we also transfused packed red cells.

Some authors have reported the onset of a bradykinin release syndrome when using filters with the AN69 membrane primed with blood; the syndrome presents as acute hypotension and can be avoided by raising the $\mathrm{pH}$ [18]. Although we use AN69 
Figure 2

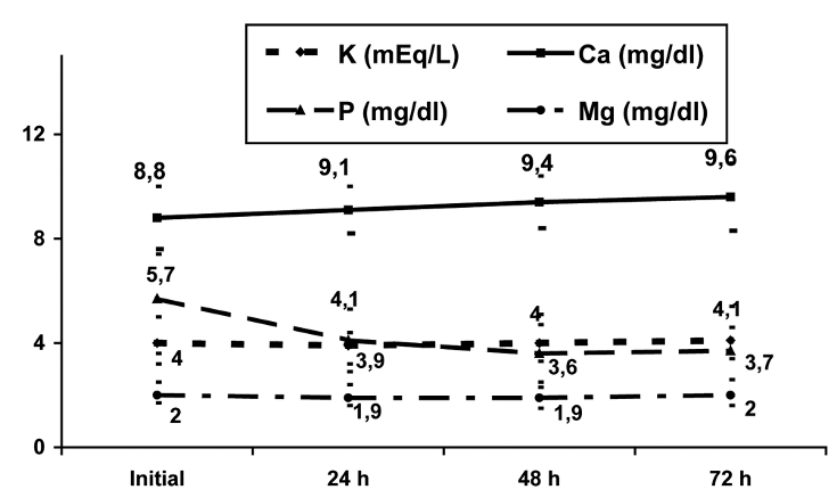

Evolution of potassium, calcium, phosphorus and magnesium serum levels during the first 72 hours of continuous renal replacement therapy. Mean and standard deviation.

membranes, we have not had this complication because we do not prime the circuit with blood.

Hypotension can also occur if excessive ultrafiltration is programmed [5] or if the machine systems that measure the volumes function incorrectly. To prevent this, both the fluid balances measured by the CRRT machine and the clinical state of the patient should be monitored continuously. According to our protocol, nurses measured hourly the input and output fluid balance and checked the ultrafiltrate volume registered by the machine. Furthermore a continuous clinical vigilance was performed. According to these data the programming of the ultrafiltration was changed by the intensivist. We think that for this reason we have not found any complications of excessive ultrafiltration in our patients.

Figure 3

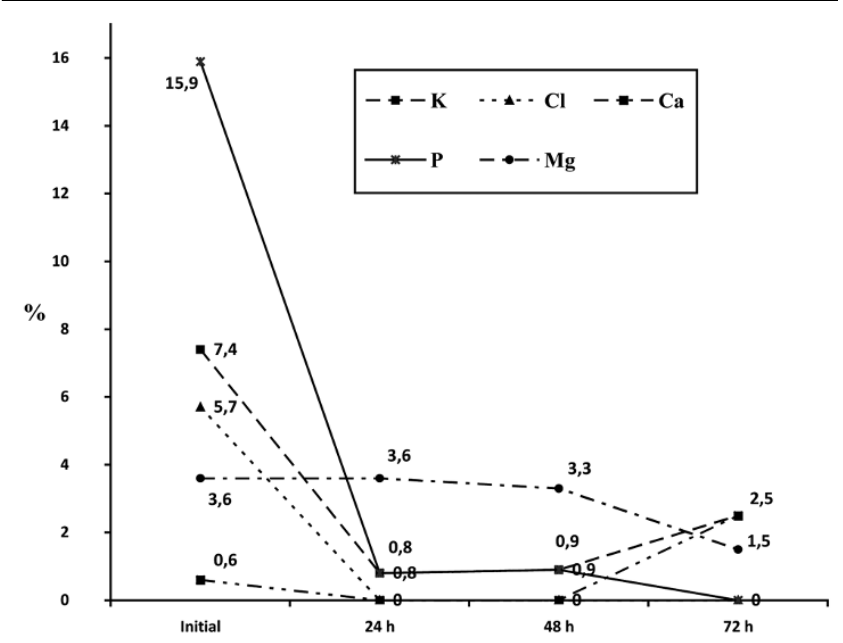

Percentage of patients with high serum levels of electrolytes during the first 72 hours of continuous renal replacement therapy. Mean and standard deviation.
Figure 4

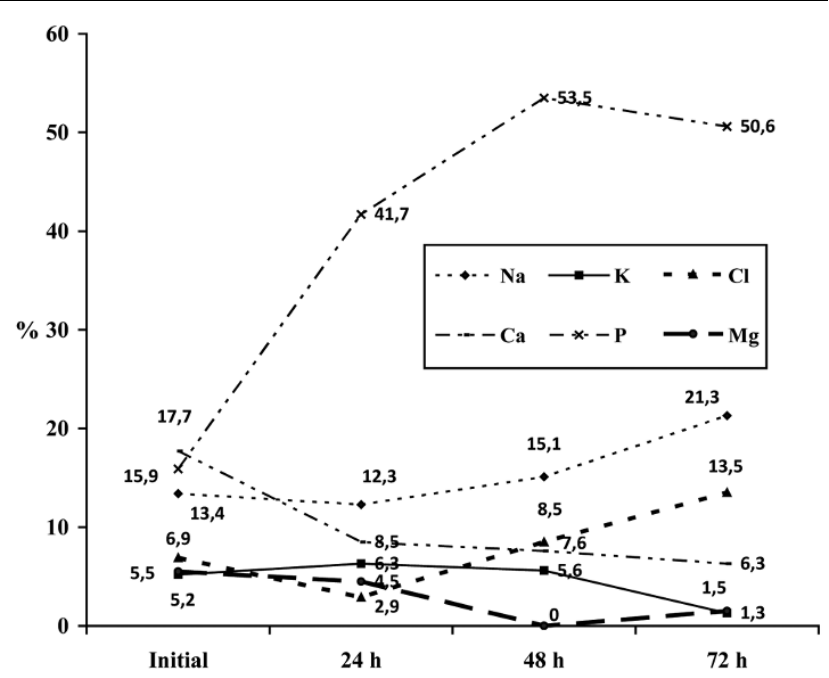

Percentage of patients with low serum levels of electrolytes during the first 72 hours of continuous renal replacement therapy. Mean and standard deviation.

The need for anticoagulation of the CRRT system, associated with the frequent alterations of coagulation that occur in these patients, increases the risk of hemorrhage. Both CRRT and heparin can produce a fall in the platelet count, as found in our study, or an alteration of platelet function. Heparin continues to be the most widely used method of anticoagulation in CRRT [19], although it has been suggested that anticoagulation using sodium citrate could reduce the risk of heparin-related hemorrhage; however, sodium citrate increases the risk of hypocalcemia and alkalosis [5,20].

Although premature coagulation of the CRRT filter is more common in children [21], 10\% of our patients presented clinically significant hemorrhage, and there was a higher mortality among these patients. In our study, we found no relationship between the incidence of hemorrhage and the platelet counts or doses of heparin used. However, an important limitation in our study is that no analysis was performed of a possible relationship between hemorrhage and other disturbances of coagulation. Moreover, it is also possible that patients with high risk of haemorrhage received a low dose of heparin and this fact could influence to not find relationship between heparin dose and bleeding. Hemorrhage in critically ill patients on CRRT is probably the consequence of several factors: a coagulation disorder, altered tissue perfusion caused by the underlying disease, and the alterations of coagulation caused by the extracorporeal circuit and anticoagulation [8,22].

Electrolyte disturbances are very common in critically ill children [23]. CRRT can be used to correct severe electrolyte disturbances, but can also produce them [24]. The risk is higher if inappropriate dialysis and/or replacement fluids are used [25], as occurred in one of our patients [12]. In our study, 
despite using balanced solutions, there was a significant fall in the levels of sodium, chloride, and phosphate, leading to the need to increase the concentration of these electrolytes in the dialysis and replacement fluids or to administer intravenous supplements. When balanced solutions are used high dose of dialysis and/or replacement fluids should not produce more electrolytes disorders. However we have not analyzed if electrolytes disorders were associated to the intensity of fluid dose prescriptions. Hyponatremia may develop if the dialysis and replacement fluids do not compensate the negative sodium balance [8]. In a previous study we found a very high incidence of hypophosphatemia in children on CRRT; this was due to the high efficacy of these techniques and the fact that the usual replacement and dialysis fluids do not contain phosphate [26]. The addition of phosphates to replacement and dialysis fluids did not cause any instability of the solutions or other complications, and reduced the incidence of hypophosphatemia and the need for intravenous phosphate supplements [26]. Therefore, as electrolyte disturbances are common in children on CRRT, periodic controls of their blood levels should be performed and the concentration in the replacement and dialysis fluids should be monitored closely in order to detect errors in the preparation of the fluids.

Other complications have been reported in patients on CRRT, such as alkalosis secondary to the bicarbonate content of the dialysis and replacement fluids [27], and errors of drug dose [28]. These complications were not analyzed in our study. Another limitation of our study is that we did not determine the incidence of hypothermia, which is more common in children on CRRT due to extracorporeal radiant heat exchange, or catheter-related infection [8].

\section{Conclusions}

We conclude that the frequency of complications in children on CRRT is high, and some of these complications can be serious. The most common are hypotension at the time of connection and electrolyte disturbances. The hemodynamic state of children on CRRT should therefore be monitored closely and frequent controls of the electrolyte concentrations should be performed.

\section{Key messages \\ - The frequency of complications in children on CRRT is high, and some of these complications can be serious. \\ - The most common complications are hypotension at the time of connection and electrolyte disturbances. The hemodynamic state of children on CRRT should be monitored closely and frequent controls of the electro- lyte concentrations should be performed.}

\section{Competing interests}

The authors declare that they have no competing interests.

\section{Authors' contributions}

MJS and JLH conceived the study and participated in the design, data collection and analysis, and drafting of the manuscript. JU, MJS, YB and MB participated in the data collection and analysis of data, and drafting of the manuscript. JMB participated in the design of the study and performed the statistical analysis. All authors read and approved the final manuscript.

\section{Acknowledgements}

To the physicians and nurses of the Paediatric Intensive Care Service of the Hospital General Universitario Gregorio Marañon de Madrid for their collaboration in the study. This study has been (partially) supported by a grant from the Spanish Health Institute Carlos iii (grant N. RD08/0072: Maternal, Child Health and Development Network) within the framework of the VI National I+D+i Research Program (2008-2011).

\section{References}

1. Walters S, Porter C, Brophy PD: Dialysis and pediatric acute kidney injury: choice of renal support modality. Pediatr Nephrol 2009, 24:37-48.

2. Strazdins V, Watson AR, Harvey B: Renal replacement therapy for acute renal failure: European guidelines. Pediatr Nephrol 2004, 19:199-207.

3. Ball EF, Kara T: Epidemiology and outcome of acute kidney injury in New Zealand children. J Paediatr Child Health 2008, 44:642-646.

4. Pichler G, Rödl S, Mache C, Trop M, Ring E, Zobel S: Two decades' experience of renal replacement therapy in paediatric patients with acute renal failure. Eur J Pediatr 2007, 166:139-144.

5. Goldstein SL: Overview of pediatric renal replacement therapy in acute renal failure. Semin Dial 2009, 22:180-184.

6. Fernández C, López-Herce J, Flores JC, Galaviz D, Ruperez M, Brandstrup KB, Bustinza A: Prognosis in critically ill children requiring continuous renal replacement therapy. Pediatr Nephrol 2005, 20:1473-1477.

7. Symons JM, Chua AN, Somers MJ, Baum MA, Bunchman TE, Benfield MR, Brophy PD, Blowey D, Fortenberry JD, Chand D, Flores FX, Hackbarth R, Alexander SR, Mahan J, McBryde KD, Goldstein SL: Demographic characteristics of pediatric continuous renal replacement therapy: a report of the prospective pediatric continuous renal replacement therapy registry. Clin J Am Soc Nephrol 2007, 2:732-738.

8. Finkel KW, Podoll AS: Complications of continuous renal replacement therapy. Semin Dial 2009, 22:155-159.

9. Pollack MM, Ruttimann UE, Getson PR: The pediatric risk of mortality (PRISM) score. Crit Care Med 1988, 16:1110-1116.

10. Shann F, Pearson G, Slater A, Wilkinson K: Pediatric index of mortality (PIM). A mortality prediction model for children in intensive care. Intensive Care Med 1997, 23:201-207.

11. Leteurtre S, Martinot A, Duhamel A, Gauvin F, Grandbastien B, Nam TV, Proulx F, Lacroix J, Leclerc F: Development of a pediatric multiple organ dysfunction score: use of two strategies. Med Decis Making 1999, 19:399-410.

12. Borrego R, Ima A, López-Herce J, Seriñá C: Hipernatremia grave: supervivencia sin secuelas neurológicas. An Pediatr (barc) 2003, 58:376-380.

13. Rey C, Alvarez F, De La Rua V, Medina A, Concha A, Díaz JJ, Menéndez S, Los Arcos M, Mayordomo-Colunga J: Mechanical complications during central venous cannulations in pediatric patients. Intensive Care Med 2009, 35:1438-1443.

14. Karapinar B, Cura A: Complications of central venous catheterization in critically ill children. Pediatr Int 2007, 49:593-599.

15. Casado-Flores J, Barja J, Martino R, Serrano A, Valdivielso A: Complications of central venous catheterization in critically ill children. Pediatr Crit Care Med 2001, 2:57-62.

16. Parienti JJ, Thirion M, Mégarbane B, Souweine B, Ouchikhe A, Polito A, Forel JM, Marqué S, Misset B, Airapetian N, Daurel C, Mira JP, Ramakers M, du Cheyron D, Le Coutour X, Daubin C, Charbonneau P, Members of the Cathedia Study Group: Femoral 
vs jugular venous catheterization and risk of nosocomial events in adults requiring acute renal replacement therapy: a randomized controlled trial. JAMA 2008, 299:2413-2422.

17. Froehlich CD, Rigby MR, Rosenberg ES, Li R, Roerig PL, Easley KA, Stockwell JA: Ultrasound-guided central venous catheter placement decreases complications and decreases placement attempts compared with the landmark technique in patients in a pediatric intensive care unit. Crit Care Med 2009, 37:1090-1096.

18. Brophy PD, Mottes TA, Kudelka TL, McBryde KD, Gardner JJ, Maxvold NJ, Bunchman TE: AN-69 membrane reactions are $\mathrm{pH}-$ dependent and preventable. Am J Kidney Dis 2001, 38:173-178.

19. Oudemans-van Straaten HM, Wester JP, de Pont AC, de Pont AC, Schetz MR: Anticoagulation strategies in continuous renal replacement therapy: can the choice be evidence based? Intensive Care Med 2006, 32:188-202.

20. Brophy PD, Somers MJ, Baum MA, Symons JM, McAfee N, Fortenberry JD, Rogers K, Barnett J, Blowey D, Baker C, Bunchman TE, Goldstein SL: Multi-centre evaluation of anticoagulation in patients receiving continuous renal replacement therapy (CRRT). Nephrol Dial Transplant 2005, 20:1416-1421.

21. Del Castillo J, López-Herce J, Cidoncha E, Urbano J, Mencía S, Santiago MJ, Bellón JM: Circuit life span in critically ill children on continuous renal replacement treatment: a prospective observational evaluation study. Crit Care 2008, 12:R93.

22. Boldt J, Menges T, Wollbruck M, Sonneborn S, Hepelmannn G: Continuous hemofiltration and platelet function in critically ill patients. Crit Care Med 1994, 22:1155-1160.

23. Ruiz Magro P, Aparicio López C, López-Herce Cid J, Martínez Campos M, Sancho Pérez L: Alteraciones metabólicas en niños criticamente enfermos. An Esp Pediatr 1999, 51:143-148.

24. Locatelli F, Pontoriero G, Di Filippo S: Electrolyte disorders and substitution fluid in continuous renal replacement therapy. Kidney Int Supp/ 1998, 66:S151-155.

25. Celik JB, Topal A, Kartal E, Yosunkaya A: Clinical outcome following the use of inadequate solutions for continuous venovenous hemodiafiltration. Ren Fail 2008, 30:959-964.

26. Santiago MJ, López-Herce J, Urbano J, Bellón JM, del Castillo J, Carrillo A: Hypophosphatemia and phosphate supplementation during continuous renal replacement therapy in children. Kidney Int 2009, 75:312-316.

27. Demirjian S, Teo BW, Paganini EP: Alkalemia during continuous renal replacement therapy and mortality in critically ill patients. Crit Care Med 2008, 36:1513-1517.

28. Barletta JF, Barletta GM, Brophy PD, Maxvold NJ, Hackbarth RM, Bunchman TE: Medications errors and patient complications with continuous renal replacement therapy. Pediatr Nephrol 2006, 21:842-845. 